\title{
Asymmetric Hydrogenation in Water by a Rhodium Complex of Sulfonated 2,2'-Bis(diphenylphosphino)-1,1'-binaphthyl (binap)
}

Kam-to Wan and Mark E. Davis*

Division of Chemistry and Chemical Engineering, California Institute of Technology, Pasadena, CA 91125, USA

The synthesis of sulfonated 2,2'-bis(diphenylphosphino)-1, $1^{\prime}$-binaphthyl (binap) is reported; a rhodium complex of this ligand is the first to perform asymmetric hydrogenation in neat water with optical yields as high as those obtained in nonaqueous solvent.

There is an increasing interest in the synthesis and application of water-soluble organometallic catalysts. ${ }^{1}$ The water solubilization of known organometallic catalysts is typically performed by incorporating highly polar functional groups such as amino, carboxylic acid, hydroxide or sulfonate into phosphine ligands. ${ }^{1}$ In addition to the advantages of being able to use an environmentally benign solvent, water-soluble complexes can be employed in various configurations, e.g. organic-aqueous two-phase,,$^{1 c, 2}$ supported aqueous phase, ${ }^{3}$ in order to acnieve effective catalyst immobilization. Here we report the synthesis of a new water soluble ligand, sulfonated $2,2^{\prime}$-bis(diphenylphosphino)-1,1'-binaphthyl (binap) ${ }^{4}$ and its use in the rhodium-catalysed asymmetric hydrogenation of prochiral olefins.

The sulfonation of $(R)$-binap requires specific reaction conditions in order to eliminate the formation of phosphine

Table 1 NMR data for various ligands and rhodium complexes

\begin{tabular}{|c|c|c|c|c|}
\hline Compound & Solvent & $\delta(\mathrm{ppm})^{a}$ & $1 J_{\mathrm{Rh}-\mathrm{P}} / \mathrm{Hz}$ & Ref. \\
\hline $\operatorname{Binap}\left(\mathrm{SO}_{3} \mathrm{Na}\right)_{4}\left(\mathrm{~L}^{1}\right)$ & $\mathrm{D}_{2} \mathrm{O}$ & $-11.0(\mathrm{~s})$ & - & This work \\
\hline$\left[\mathrm{Rh}\left(\mathrm{L}^{1}\right)(\mathrm{cod})\right] \mathrm{ClO}_{4}$ & $\mathrm{D}_{2} \mathrm{O}$ & 31.0 (d) & 144 & This work \\
\hline$\left[\mathrm{Rh}\left(\mathrm{L}^{1}\right)\left(\mathrm{D}_{2} \mathrm{O}\right)_{2}\right] \mathrm{ClO}_{4}$ & $\mathrm{D}_{2} \mathrm{O}$ & $51.0(\mathrm{~d})$ & 196 & This work \\
\hline$(S)$-Binap $\left(\mathrm{L}^{2}\right)$ & $\mathrm{C}_{6} \mathrm{D}_{6}-\mathrm{CD}_{3} \mathrm{OD}(4: 1)$ & $-12.8(\mathrm{~s})$ & - & $4(b)$ \\
\hline$\left[\mathrm{Rh}\left(\mathrm{L}^{2}\right)(\mathrm{nbd})\right] \mathrm{ClO}_{4}{ }^{b}$ & $\mathrm{CD}_{3} \mathrm{OD}$ & $25.1(\mathrm{~d})$ & 156 & $4(b)$ \\
\hline$\left[\mathrm{Rh}\left(\mathrm{L}^{2}\right)(\mathrm{MeOH})_{2}\right] \mathrm{ClO}_{4}$ & $\mathrm{CD}_{3} \mathrm{OD}$ & $53.1(\mathrm{~d})$ & 206 & 5 \\
\hline Tetrasulfonated $(S, S)$-cyclobutanediop $\left(\mathrm{L}^{3}\right)^{c}$ & $\mathrm{D}_{2} \mathrm{O}$ & $-20.2(\mathrm{~s})$ & - & 5 \\
\hline$[\mathrm{Rh}(\operatorname{cod}) \mathrm{Cl}]_{2}+\left(\mathrm{L}^{3}\right)$ & $\mathrm{D}_{2} \mathrm{O}$ & $20.2(\mathrm{~d})$ & 144 & 5 \\
\hline$\left[\mathrm{Rh}\left(\mathrm{L}^{3}\right)\left(\mathrm{H}_{2} \mathrm{O}\right)_{2}\right]^{+}$ & $\mathrm{D}_{2} \mathrm{O}$ & $43.5(d)$ & 182 & 5 \\
\hline Tetrasulfonated $(S, S)$-bdpp $\left(\mathrm{L}^{4}\right)^{d}$ & $\mathrm{D}_{2} \mathrm{O}$ & $0.7(\mathrm{~s})$ & - & 5 \\
\hline$[\mathrm{Rh}(\operatorname{cod}) \mathrm{Cl}]_{2}+\mathrm{L}^{4}$ & $\mathrm{D}_{2} \mathrm{O}$ & 29.3 (d) & 144 & 5 \\
\hline$\left[\mathrm{Rh}\left(\mathrm{L}^{4}\right)\left(\mathrm{H}_{2} \mathrm{O}\right)_{2}\right]^{+}$ & $\mathrm{D}_{2} \mathrm{O}$ & $53.2(\mathrm{~d})$ & 185 & 5 \\
\hline
\end{tabular}

a $31 \mathrm{P}$ NMR chemical shifts relative to $\mathrm{H}_{3} \mathrm{PO}_{4}$; downfield shifts are positive. ${ }^{b}$ nbd $=$ norbornadiene. ${ }^{c}(S, S)$-Cyclobutanediop $(S, S)$-1,2-bis(diphenylphosphinomethyl)cyclobutane. ${ }^{d}$ bdpp $=$ bis(2-diphenylphosphinoethyl)(phenyl)phosphine. 
Table 2 Hydrogenation of 2-acetamidoacrylic acid and its methyl ester at room temperature under 1 atm $\mathrm{H}_{2}(S, S)$-1,2-bis(diphenylphosphinomethyl)cyclobutane

\begin{tabular}{|c|c|c|c|c|}
\hline Substrate ${ }^{a}$ & Solvent & $\begin{array}{l}\text { [Substrate]/ } \\
{\text { moll }{ }^{-1}}^{-1}\end{array}$ & $\begin{array}{l}\text { Substrate/ } \\
\text { catalyst }\end{array}$ & E.e. $(\%)^{b}$ \\
\hline 1 & $\mathrm{H}_{2} \mathrm{O}$ & 0.007 & 25 & $70.4,68.0$ \\
\hline 1 & $7: 1 \mathrm{H}_{2} \mathrm{O}-\mathrm{MeOH}$ & 0.017 & 40 & 67.0 \\
\hline $\mathbf{1}$ & $1: 1 \mathrm{H}_{2} \mathrm{O}-\mathrm{MeOH}$ & 0.017 & 41 & 56.0 \\
\hline $\mathbf{1}$ & $1: 2 \mathrm{H}_{2} \mathrm{O}-\mathrm{MeOH}$ & 0.042 & 75 & 55.0 \\
\hline 1 & $\mathrm{MeOH}$ & 0.017 & 40 & 58.0 \\
\hline 1 & $\mathrm{EtOH}$ & 0.017 & 41 & 58.6 \\
\hline 1 & $\mathrm{EtOH}$ & 0.031 & 76 & $35.0^{e, f}(264)^{d}$ \\
\hline 1 & 1:1 EtOH-tetrahydrofuran & - & 100 & $67.0 \mathrm{~g}$ \\
\hline 2 & $\mathrm{H}_{2} \mathrm{O}$ & 0.017 & 75 & $68.5,68.3^{c}$ \\
\hline $\mathbf{2}$ & $\mathrm{H}_{2} \mathrm{O}$ & 0.039 & 76 & $69.0(41),{ }^{d} 68.0^{c}(45)^{d}$ \\
\hline 2 & $4: 1 \mathrm{H}_{2} \mathrm{O}-\mathrm{MeOH}$ & 0.017 & 76 & 61.2 \\
\hline 2 & $\mathrm{MeOH}$ & 0.017 & 75 & 47.8 \\
\hline 2 & $\mathrm{EtOH}$ & 0.031 & 75 & $56.0(302)^{d}$ \\
\hline 2 & $\mathrm{EtOH}$ & 0.031 & 76 & $20.0^{e, h}(389)^{d}$ \\
\hline 2 & $\mathrm{EtOH}$ & 0.031 & 76 & $22.0^{e, f}(467)^{d}$ \\
\hline
\end{tabular}

a Substrates: 1, $\mathrm{CH}_{2}=\mathrm{C}(\mathrm{NHAc}) \mathrm{CO}_{2} \mathrm{H} ; 2, \mathrm{CH}_{2}=\mathrm{C}(\mathrm{NHAc}) \mathrm{CO}_{2} \mathrm{Me} .{ }^{b}$ Conversions $100 \%$ and the product configuration is mainly $S$. $c$ Repeat experiments with different ligand syntheses and/or reaction runs. $d$ Initial turnover frequency $\left(\mathrm{h}^{-1}\right)$. e $[\mathrm{Rh}\{(R)-$ binap $\}$ (solvent $\left.)_{2}\right] \mathrm{ClO}_{4}$ as catalyst precursor. $f$ Synthesized here. $\left.g[\mathrm{Rh}\{(R) \text {-binap }\} \text { (solvent })_{2}\right]^{+}$as catalyst precursor. $\mathrm{H}_{2}$ pressure 4 atm. From Ref. $4 b .{ }^{h}$ Obtained from Aldrich.

oxides and to achieve a high yield of a single phosphine species. $\dagger$ Elemental analysis (Galbraith Lab., Knoxville, TN) of the recovered solid is consistent with the sample containing ca. $85 \%$ tetrasulfonated binap [calculated for binap $\left(\mathrm{SO}_{3}^{-}\right.$ $\mathrm{Na})_{4}: \mathrm{S} / \mathrm{P}: \mathrm{Na} / \mathrm{P}: \mathrm{C} / \mathrm{Na}=2: 2: 11 ;$ found, $\mathrm{S} / \mathrm{P}: \mathrm{Na} / \mathrm{P}: \mathrm{C} / \mathrm{Na}=$ $2.34: 2.02: 11.31]$. This result is in agreement with the ${ }^{31 P}$ NMR spectrum that shows a single major resonance at $\delta \mathrm{ca}$. -11.1 with a second small peak around $\delta-12.7$ (relative intensities are $86: 14)$. The ${ }^{33} \mathrm{~S}$ NMR spectrum of the oxidized form of this sample (in $\mathrm{D}_{2} \mathrm{O}$ ) indicates that no sodium sulfate is present, to at least the detection limits of NMR (150000 scans employed) and that no further information on the sample composition is possible because the sulfate groups on the binap give a broad peak around $\delta-13$ (relative to ammonium sulfate). Because of the difference in $\pi$-stabilization energy, the phenyl rings in binap are relatively more reactive towards electrophilic aromatic substitution by sulfur trioxide as compared to the naphthyl rings. Thus, we speculate that in the major species obtained, only the four phenyl rings in the binap are sulfonated under the conditions listed above. Otherwise, at least two distinct signals with equal intensities should appear in the ${ }^{31} \mathrm{P}$ NMR spectrum. Although definitive assignments are not yet possible owing to the complexity of the ${ }^{1} \mathrm{H}$ and ${ }^{13} \mathrm{C}$ NMR spectra, our NMR data are consistent with the premise that only the four phenyl rings are sulfonated in the major species obtained in $85 \%$ abundance. The remaining species is likely to be penta- or hexa-sulfonated binap with one or two extra sulfonated group(s) on the naphthyl ring(s). As the origin of chiral recognition is attributed to the interaction of the four phenyl rings and the substrate, the presence of any extra sulfonated groups on the naphthyl rings is unlikely to affect the enantioselectivity. In fact, similar activity and selectivity are found with catalysts prepared from several batches of ligand with different ratios of major to minor species (vide infra).

† The sulfonation of $(R)$-binap was accomplished by dissolving $(R)$-binap $(1 \mathrm{~g})$ in concentrated sulfuric acid $(3.5 \mathrm{ml})$ with subsequent dropwise addition of $15 \mathrm{ml}$ (during $2-3 \mathrm{~h}$ ) of fuming sulfuric acid (40 wt \% sulfur trioxide in concentrated sulfuric acid) and stirring for 3 days at $10^{\circ} \mathrm{C}$ under argon. The reaction was quenched by pouring the solution into $100 \mathrm{ml}$ of ice-cooled water and the product neutralized by dropwise addition of aqueous sodium hydroxide (50 wt $\% \mathrm{NaOH}$ ) until a pH of 7 was reached. The volume of the solution was reduced to $30 \mathrm{ml}$ in vacuo and methanol $(100 \mathrm{ml})$ added to precipitate any sodium sulfate present. Sulfonated $(R)$-binap was recovered as a solid by vacuum drying the filtered methanolic solution.
The rhodium binap $\left(\mathrm{SO}_{3} \mathrm{Na}\right)_{4}$ catalyst was prepared as follows. [ $\mathrm{Rh}(\operatorname{cod}) \mathrm{Cl}]_{2}(\mathrm{cod}=$ cycloocta-1,5-diene $)$ was treated with 2 equiv. of $(R)$-binap $\left(\mathrm{SO}_{3} \mathrm{Na}\right)_{4}$ in water at room temperature with an excess of sodium perchlorate. The cationic species $\left[\mathrm{Rh}\left\{(R)\right.\right.$-binap $\left.\left.\left(\mathrm{SO}_{3} \mathrm{Na}\right)_{4}\right\}(\operatorname{cod})\right]\left(\mathrm{ClO}_{4}\right)$ is formed and contacted with one atmosphere of dihydrogen to give the active catalyst $\left[\mathrm{Rh}\left\{(R) \text {-binap }\left(\mathrm{SO}_{3} \mathrm{Na}\right)_{4}\right\}\left(\mathrm{H}_{2} \mathrm{O}\right)_{2}\right]^{+}$. Further addition of 2 equiv. of $(R)$-binap $\left(\mathrm{SO}_{3} \mathrm{Na}\right)_{4}$ or initial mixing of 4 equiv. with $[\mathrm{Rh}(\operatorname{cod}) \mathrm{Cl}]_{2}$ gives the inactive complex $\left[\mathrm{Rh}\left\{(R) \text {-binap }\left(\mathrm{SO}_{3} \mathrm{Na}\right)_{4}\right\}_{2}\right]^{+}$. Assignments of these species are based on the data in Table 1.

Asymmetric hydrogenations of 2-acetamidoacrylic acid and its methyl ester were conducted at room temperature and one atmosphere of dihydrogen in batch autoclaves. The conversion was measured by ${ }^{1} \mathrm{H}$ NMR spectroscopy and the enantiomeric excess (e.e.) determined by gas chromatography using a J. \& W. Scientific CDX-B chiral capillary column after derivatization of the reaction products. ${ }^{6}$

Table 2 shows the results of hydrogenating 2 -acetamidoacrylic acid and its methyl ester using the water-soluble rhodium complex with $(R)$-binap $\left(\mathrm{SO}_{3} \mathrm{Na}\right)_{4}$. Like the unsulfonated version of the rhodium catalyst, the enantioselection favours the $(S)$-enantiomer. ${ }^{4 b}$ However, we do not observe a dependence of e.e. on the concentration of substrate $\ddagger$ as is reported for the unsulfonated rhodium-binap catlayst. ${ }^{4 b}$ Note that the results in Table 2 illustrate that the e.e. in pure water is approximately the same as observed with the unsulfonated rhodium-binap catalyst in ethanol $\left(70.4-68.0 \%\right.$ vs. $\left.67.0 \%{ }^{4 b}\right)$. This is the first example of asymmetric hydrogenation in neat water where the optical yield obtained is as high as that observed in nonaqueous solvents. Normally, large losses in enantioselectivity result when using water as solvent. ${ }^{2 b .8}$ Additionally, loss in enantioselectivity is also reported with sulfonation of phosphine ligands. ${ }^{8 a, d}$ Here, not only is high enantioselectivity retained upon sulfonation and use in neat water, the e.e. obtained with the rhodium-binap $\left(\mathrm{SO}_{3} \mathrm{Na}\right)_{4}$ catalyst increases with the proportion of water in the solvent; the e.e. is $70.4 \%$ in pure $\mathrm{H}_{2} \mathrm{O}$ compared to $58.0 \%$ in neat methanol. The trends observed with substrate 1 are also obtained with substrate 2 .

$\ddagger$ The e.e. was found to be $58 \pm 1 \%$ for substrate 1 in $\mathrm{MeOH}$ solvent over the substrate concentration range of $0.003-0.078 \mathrm{~mol} \mathrm{l}^{-1}, 49 \pm$ $2 \%$ for substrate 2 in $\mathrm{MeOH}$ solvent over a substrate concentration range of $0.007-0.134 \mathrm{~mol}^{-1}$ and $68 \pm 1 \%$ for substrate 2 in $\mathrm{H}_{2} \mathrm{O}$ solvent over a substrate concentration range of $0.017-0.039 \mathrm{~mol} \mathrm{l}^{-1}$. 
We attempted a comparison between the hydrogenation behaviour of unsulfonated and sulfonated $(R)$-binap rhodium complexes in ethanol.\& Unfortunately, the unsulfonated complexes prepared here or purchased from Aldrich gave very low e.e.s under one atmosphere of dihydrogen pressure as compared with that reported under four atmospheres. ${ }^{4 b}$ Because of this, we are only able to compare initial turnover frequencies in water and ethanol for the sulfonated $(R)$-binap catalyst (see Table 1). The solubility of dihydrogen in ethanol and water at $25^{\circ} \mathrm{C}$ at $1 \mathrm{~atm}$ is $38.2 \times 10^{-4}$ and $8.53 \times 10^{-4}$ mol $1^{-1}$, respectively. ${ }^{9}$ The cause of the low e.e. is unclear but catalyst decomposition is likely since a black precipitate appeared during the course of one of the reactions. Thus, the loss in initial turnover frequency when water is used as solvent is most likely due to the lowering of the dihydrogen solubility. Support for this work was provided by the NSF Alan T. Waterman Award to M. E. D. We thank Professor John Bercaw for helpful discussions.

Received, 7th April 1993; Com. 3/02021E

$\S$ A direct comparison between the unsulfonated and the sulfonated $(R)$-binap rhodium complexes is not possible in water because unsulfonated $(R)$-binap is not soluble in water.

\section{References}

1 F. Joo and Z. Toth, J. Mol. Catal., 1980, 8, 369; D. Sinou, Bull. Soc. Chim. Fr., 1987, 480; P. Kalck and F. Monteil, Adv. Organomet. Chem., 1992, 34, 219.

2 I. Toth, B. E. Hanson and M. E. Davis, (a) Catal. Lett., 1990, 183; (b) Tetrahedron Asymmetry, 1990, 1, 913.

3 J. P. Arhancet, M. E. Davis, J. S. Merola and B. E. Hanson, (a) Nature 1989, 339, 454; (b) J. Catal., 1990, 121, 327; J. P. Arhancet, M. E. Davis and B. E. Hanson, (c) J. Catal., 1991, 129, 94; (d) J. Catal., 1991, 129, 100; (e) M. E. Davis, CHEMTECH, $1992,498$.

4 (a) A. Miyashita, A. Yasduda, H. Takaya, K. Toriumi, T. Itok, T. Souchi and R. Noyori, J. Am. Chem. Soc., 1980, 102, 7932; A. Miyashita, H. Takaya, T. Souchi and R. Noyori, Tetrahedron, $1984,40,1245$.

5 Y. Amrani, L. Lecomte, D. Sinou, J. Bakos, I. Toth and B. Heil, Organometallics, $1989,8,542$.

6 S. El Baba, J. C. Poulin and H. B. Kagan, Tetrahedron, 1984, 40, 4275 .

7 T. Ikariya, Y. Ishii, H. Kawano, T. Arai, M. Saburi, S. Yoshikawa, S. Akutagawa, J. Chem. Soc., Chem. Commun., 1985, 922.

8 (a) Y. Amrani and D. Sinou, J. Mol. Catal., 1984, 24, 231; (b) D. Sinou and Y. Amrani, J. Mol. Catal., 1986, 36, 319; (c) R. Benhanza, Y. Amrani and D. Sinai, J. Organomet. Chem., 1985, 288, C37; $(d)$ L. Lecomte and D. Sinou, J. Organomet. Chem., 1988, 370, 277; (e) G. Oehme, E. Paetzold and R. Selke, J. Mol. Catal., 1992, 71, L1.

9 P. G. T. Fogg and W. Gerrard, Solubility of Gases in Liquids, Wiley, New York, 1991. 